\title{
DETERMINASI MINAT BELAJAR DAN SIKAP TERHADAP PRESTASI BELAJAR MELALUI KREATIVITAS MAHASISWA
}

\section{Nurhayati, Lias Hasibuan, Kemas Imron Rosyadi}

Universitas Islam Negeri Sultan Thaha Saifuddin, Indonesia

Email: nurhayatirazeq@gmail.com,1has10@yahoo.co.id, kemasimronrosadi@uinjambi.ac.id

\begin{abstract}
Abstrak
Kemajuan suatu bangsa sangat ditentukan oleh sejauhmana sistem pendidikan yang diterapkan mampu mencetak sumber daya manusia yang unggul. Tujuan penelitian ini adalah untuk adalah meneliti seberapa penting Pendidikan yang dihasilkan. Metode penelitian ini menggunakan metode survey model kausal dengan menggunakan teknik analisis jalur (path analysis). Berdasarkan kepada alasan penelitian ini bertujuan untuk konfirmasi model teoretik dengan data empiris dan sampel berjumlah 100 orang mahasiswa IAI Abdullah Said Batam. Minat belajar mendeterminasi secara langsung terhadap kreativitas. Sikap mendeterminasi secara langsung terhadap kreativitas. Kreativitas mendeterminasi secara langsung terhadap prestasi belajar. Minat belajar tidak mendeterminasi secara langsung terhadap prestasi belajar. Sikap tidak mendeterminasi secara langsung terhadap prestasi belajar. Sehingga minat belajar dan kteativitas mempengeruhi prestasi belajar.
\end{abstract}

Kata Kunci: minat belajar; sikap; kreativitas; prestasi belajar

\section{Abstract}

The progress of a nation is largely determined by the extent to which the education system applied is able to print superior human resources. The purpose of this research is to examine how important education is produced. This research method uses a causal model survey method using path analysis techniques. Based on the reason of this study aims to confirm the theoretical model with empirical data and a sample of 100 IAI abdullah said batam students. Learning interests determine directly to creativity. Direct attitude to creativity. Creativity determines directly to learning achievement. Interest in learning does not determine directly to learning achievement. Attitudes do not determine directly to learning achievement. So that the interest in learning and kteativitas is therefore learning achievement.

Keywords: interest in learning; attitude; creativity; learning achievement;

\section{Received: 2021-09-22; Accepted: 2021-10-05; Published: 2021-10-20}

\begin{tabular}{ll}
\hline How to cite: & Nurhayati. N., Hasibuan. L., \& Rosadi. R.I., (2021) Determinasi Minat Belajar dan Sikap Terhadap \\
& Prestasi Belajar Melalui Kreativitas Mahasiswa, Syntax Idea, 3(10), https://doi.org/10.36418/syntax- \\
& idea.v3i10.1503 \\
E-ISSN: & 2684-883X \\
Published by: & Ridwan Institute
\end{tabular}




\section{Pendahuluan}

Kemajuan suatu bangsa sangat ditentukan oleh sejauhmana sistem pendidikan yang diterapkan mampu mencetak sumber daya manusia (SDM) yang unggul. Dengan SDM yang uggul, sebuah bangsa akan mampu menghadapi berbagai tantangan dari perkembangan tatanan dunia yang semakin kompleks serta mampu tampil sebagai bagian dari kemajuan ilmu pengetahuan dan teknologi (IPTEK). Untuk mewujudkan itu, sistem pendidikan harus dapat menyelenggarakan program pendidikan yang berkualitas dari mulai jenjang anak usia dini sampai perguruan tinggi (Imam, 2021).

Sumber daya manusia merupakan aset penting bagi organisasi. Mereka membutuhkan perhatian dari berbagai pihak agar prestasinya dapat dimaksimalkan sehingga tujuan organisasi tercapai. Berdasarkan hal tersebut, manajemen sumber daya manusia diperlukan untuk meningkatkan efektivitas sumber daya manusia dalam sebuah organisasi (Maesaroh, 2013).

Kaitannya dengan tujuan pendidikan adalah untuk mencerdaskan kehidupan bangsa sekaligus untuk meningkatkan harkat dan martabat manusia. Sebagai mana yang tercantum dalam UU NO. 20. Tahun 2003 pasal 3. Pendidikan nasional berfungsi mengembangkan kemapuan dan membentuk watak serta peradaban bangsa yang bermartabat dalam rangka mencerdaskan kehidupan bangsa. Bertujuan untuk berkembangnya potensi untuk peserta didik agar menjadi manusia yang beriman dan bertaqwa kepada Tuhan Yang Maha Esa, Berakhlak mulia, sehat, berilmu, cakap, kreatif, mandiri dan menjadi warga Negara yang demokratis serta bertanggungjawab. Menurut (Sukmadinata, 2019) prestasi belajar adalah "merupakan kecakapan-kecakapan potensial, kemampuan atau kapasitas yang dimiliki mahasiswa". Pada hakekatnya prestasi belajar merupakan usaha yang dilakukan mahasiswa untuk memperoleh nilai yang baik. Keberhasilan mahasiswa dalam belajar ditentukan oleh faktor internal dan faktor eksternal.

Minat merupakan salah satu aspek psikologis yang mempengaruhi kualitas pencapaian hasil belajar siswa. Minat merupakan sikap batin yang diekspresikan dan menunjukkan bahwa seseorang menyukai dan memberi perhatian besar terhadap suatu hal atau aktivitas. Selain itu timbul perasaan senang untuk mengenang beberapa hal atau aktivitas tersebut dan sekaligus terlibat sepenuhnya dengan kegiatan yang menyangkut hal atau aktivitas tersebut (Arifin, 2018).

Mengingat pentingnya minat tumbuh dalam diri seseorang, maka seseorang siswa pun sangat diharapkan memiliki minat terhadap berbagai hal atau aktivitasnya. Daya mengingat bahan pelajaran juga bertalian erat dengan konsentrasi terhadap pelajaran. Ingatan mungkin tercapai kalau siswa berminat terhadap pelajarannya. Dengan kata lain minat memilki peranan mempermudah dan memperkuat pelajarannya melekat dalam ingatan (Arifin, 2018).

Sikap belajar adalah keadaan kesiapan mental melalui pengalaman yang menimbulkan pengaruh secara langsung atau dinamis, atas dasar tanggapan terhadap semua obyek yang menghubungkan antara data dan situasi belajar (Syarifuddin, 2016). Sikap belajar menggerakkan seseorang untuk bertindak dalam proses pembelajaran, 
disertai perasaan-perasaan tertentu dalam menanggapinya, terbentuk atas dasar pengalaman. Sikap belajar tidak ikut dilahirkan bersama manusia, melainkan dibentuk sepanjang perkembangan setiap individu. Sangat besar perannya, bila sudah terbentuk ikut menentukan cara berperilaku terhadap suatu obyek yaitu proses pembelajaran (Syarifuddin, 2016). Beberapa faktor yang mempengaruhi sikap belajar adalah pengalaman pribadi, pengaruh orang lain yang dianggap penting, pengaruh budaya, media massa, lembaga pendidikan dan keagamaan, dan pengaruh emosi (Saifuddin Azwar, 2010).

Pengalaman belajar ideal harus ditempuh melalui aktivitas yang melibatkan beberapa unsur pembentuk sikap belajar yaitu mendengarkan, memandang, menggunakan indra pendamping, membaca, menulis/mencatat, mengingat, berpikir, berlatih/mempraktikkan (Tadjab, 1994). Komponen yang membentuk sikap belajar adalah afeksi/perasaan, kognisi/pengenalan, dan konasi/tingkah laku (Walgito, 2004). Prestasi belajar adalah kemampuan menguasai pengetahuan/ketrampilan mata pelajaran yang terlihat dalam nilai tes (Syarif, 2012), nilai sebagai perumusan akhir kemajuan dalam waktu tertentu (Indrayani, 2012), hasil terukur melakukan kegiatan yang merupakan kemampuan nyata (Muhibbin, 2010).

Prestasi belajar dipengaruhi faktor internal dan eksternal. Faktor eksternal termasuk sekolah, meliputi kurikulum, alat mengajar, metode mengajar, metode belajar (Slameto, 2010). Faktor pendekatan pembelajaran bisa pula menjadi faktor pengaruh, termasuk strategi dan metode melakukan kegiatan pembelajaran (Maesaroh, 2013). Selain itu, faktor internal peran konsep diri dan pengakuan prestasi serta jenis kelamin, dapat menjadi faktor pengaruh pula, termasuk kecemasan dan motivasi yang dimiliki (Pulungan, 2015). Dalam proses pembelajaran, senantiasa diusahakan agar mahasiswa mampu melakukan transfer ilmu secara positif, sehingga dapat menunjukkan prestasi belajar bagus, dapat menggunakan hasil belajar untuk kehidupan. Keberadaan penilaian di perguruan tinggi dianggap mutlak, karena dengan penilaian dapat diketahui perkembangan mahasiswa dalam menerima ilmu dosen. Evaluasi pada akhir rentang program studi, bertujuan menentukan prestasi mahasiswa dalam mengikuti rentang program studi yang direncanakan. Prestasi belajar yang berupa indeks prestasi dinyatakan dalam angka.

Mempersiapkan tenaga profesional ortotis prostetis, dibutuhkan pendidikan yang menghasilkan lulusan dengan prestasi belajar tinggi. Mutu lulusan sangat penting diperhitungkan, sehingga pendidikan sebagai ujung tombak pencetak tenaga profesional memegang peran penting. Salah satu faktor pengukur keberhasilan proses pembelajaran adalah prestasi belajar. Faktor pengaruh prestasi belajar mahasiswa adalah eksternal dan internal. Faktor eksternal berasal dari luar mahasiswa yaitu keluarga, masyarakat, dan tempat pendidikan berupa metode mengajar, sarana prasarana pembelajaran, kedisiplinan termasuk kebijakan (Slameto, 2010). Faktor internal berasal dari diri mahasiswa, termasuk faktor fisik dan psikis. Faktor fisik berupa kesehatan dan cacat tubuh; faktor psikis berupa intelegensi, bakat, motivasi, kreativitas dan sikap belajar (Susilowati, 2015). Faktor internal lebih dominan (Suryosubroto, 2008). 
Dunia perguruan tinggi, dosen memberi peluang mahasiswa untuk mengeksplor ilmu yang secara garis besar telah diberikan. Mahasiswa dituntut memiliki kreativitas belajar dalam mencari berbagai sumber belajar, untuk mengkayakan ilmunya. Kreativitas belajar, mendukung keberhasilan seseorang dalam mencapai prestasi belajar tinggi. Namun, memiliki kreativitas belajar tanpa tindakan tak ada arti. Sikap belajar mewarnai dan menjiwai semangat untuk melaksanakan kreativitas belajar. Sikap positif dalam belajar, sangat mendukung dan mendorong munculnya tindakan untuk kreativitas belajar yang tersimpan. Sebaliknya, kreativitas belajar yang telah muncul sebagai tindakan, membuat seseorang menjadi lebih percaya diri, sehingga bersikap positif terhadap ilmu yang diterimanya.

Pentingnya penelitian dilakukan agar dosen dapat meningkatkan kreativitas mahasiswanya untuk meningkatkan prestasi belajarnya yang didukung oleh minat dan sikap belajar yang baik. Penelitian ini penting untuk dilakukan agar para dosen bisa meningkatkan kreativitas mahasiswanya, memotovasi minta dan memperbaiki sikap belajarnya untuk meningkatkan prestasi belajarnya.

Penelitian terdahulu tentang minat belajar sebagai determinan hasil belajar siswa (Learning Interest as Determinant Student Learning Outcomes) di Sekolah Menengah Kejuruan (SMK) di Bandung. Hasil penelitiannya bahwa minat belajar dalam penelitian ini berada pada kategori sangat tinggi. Minat belajar tersebut diukur menggunakan empat indikator yang dijadikan ukuran yaitu ketertarikan untuk belajar, perhatian dalam belajar, motivasi belajar dan pengetahuan. Sementara hasil belajar dalam penelitian ini berada pada kategori sedang. Hasil belajar siswa tersebut diukur berdasarkan hasil ujian akhir semester ganjil (Nurhasanah \& Sobandi, 2016).

Minat belajar berpengaruh positif dan signifikasn terhadap hasil belajar. Dengan demikian adanya peningkatan minat belajar maka akan diikuti oleh peningkatan hasil belajar. Artinya semakin baik minat belajar siswa, maka berdampak kepada hasil belajar siswa yang semakin baik (Qomariah \& Sudiarditha, 2016).

Hasil penelitian menunjukkan bahwa salah satu indikator pada variabel minat belajar yaitu perhatian dalam belajar mendapat skor terendah dibandingkan dengan indikator variabel minat belajar lainnya. Oleh karena itu perlu untuk menumbuhkan dan mengembangkan perhatian siswa dalam proses pembelajaran. Sebaiknya perhatian dalam mengikuti proses pembalajaran harus timbul atas dasar kesadaran yang tinggi dari siswa tersebut untuk belajar. Selanjutnya diharapkan guru mampu memberikan motivasi dan bimbingan kepada siswa, tujuannya agar siswa memiliki hasrat yang lebih tinggi untuk belajar sehingga perhatian dalam belajarnya akan semakin lebih baik.

Dipenelitian terdahulu minat belajar sangat berpengaruh positif terhadap hasil belajar belum ada pengaruh sikap dan kreativitas mahasiswa untuk menghasilkan prestasi belajar.

\section{Metode Penelitian}

Jenis penelitian pada penelitian ini adalah penelitian kausalitas yaitu penelitian yang disusun untuk meneliti kemungkinan adanya hubungan sebab akibat antar variabel 
(Sanusi, 2011). Metode penelitian ini menggunakan metode survey model kausal dengan menggunakan teknik analisis jalur (path analysis). Berdasarkan kepada alasan penelitian ini bertujuan untuk konfirmasi model teoretik dengan data empirk. Penelitian ini berupaya menguji hipotesis yang digunakan dimana penelitian ini akan mengambil sampel dari suatu populasi dan menggunakan kuesioner sebagai pengumpul data yang pokok (Rivaldo, 2021).

Menurut (Sugiyono, 2017) populasi adalah wilayah generalisasi yang terdiri atas obyek atau subyek yang mempunyai kualitas dan karakteristik tertentu yang ditetapkan oleh peneliti untuk dipelajari dan kemudian ditarik kesimpulannya. Populasi pada penelitian ini adalah mahasiswa aktif Tahun 2021 Institut Agama Islam Abdullah Said Batam yang berjumlah 132 orang. Menurut (Sugiyono, 2017) sampel ialah bagian dari karakteristik tertentu didalam keseluruhan populasi. Pengambilan sampel pada penelitian ini adalah probability sampling yaitu metode simple random sampling dan sampel yang berjumlah 100 orang.

\section{Hasil dan Pembahasan}

Berdasarkan data analisis konsistensi internal diperoleh hasil bahwa variabel X1 memiliki nilai reliabilitas komposit sebesar 0,803>0,600 maka variabel X1 adalah reliabel, kemudian variabel X2 memiliki nilai reliabilitas komposit sebesar 0,749 > 0,600 maka variabel X2 adalah reliabel, variabel Y memiliki nilai reliabilitas komposit sebesar 0,886 > 0,600 maka variabel $\mathrm{Y}$ adalah reliabel, variabel $\mathrm{Z}$ memiliki nilai reliabilitas komposit sebesar 0,889 >0,600 maka variabel $\mathrm{Z}$ adalah reliabel. Nilai outer loading untuk variabel X1, X2, Z, Y dimana nilai seluruh item butir pertanyaan pada 4 variabel yang diuji lebih besar dari 0,4 maka semua indikator pada 4 variabel dinyatakan valid.

Tabel 1

Inner VIF Values

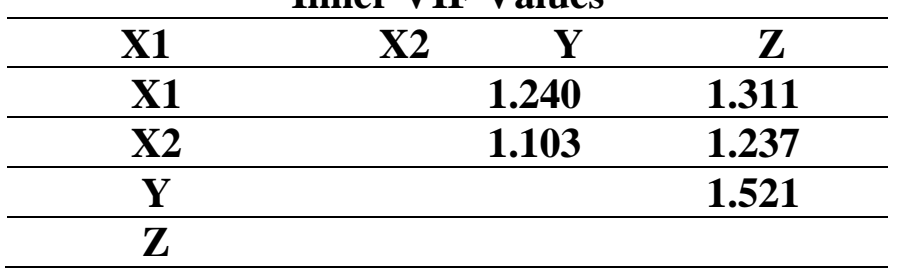

Sumber: Data primer diolah, 2021

Berdasarkan hasil pengolahan data pada tabel 1 dapat diperoleh VIF sebagai berikut.

1. VIF untuk korelasi X1 dengan $\mathrm{Z}$ adalah $1.311<5,00$ (tidak terjadi masalah kolinearitas)

2. VIF untuk korelasi $\mathrm{X} 2$ dengan $\mathrm{Z}$ adalah $1.237<5,00$ (tidak terjadi masalah kolinearitas)

3. VIF untuk korelasi $\mathrm{Y}$ dengan $\mathrm{Z}$ adalah $1.521<5,00$ (tidak terjadi masalah kolinearitas)

Dengan demikian, dari data-data di atas, model struktural dalam kasus ini tidak mengandung masalah kolinearitas. 
Pengujian signifikansi koefisien jalur model structural (Structural Model Path Coeffisient). Pengujian ini untuk menentukan koefisien jalur dari model structural, tujuannya adalah untuk menguji signifikansi semua hubungan atau pengujian hipotesis.

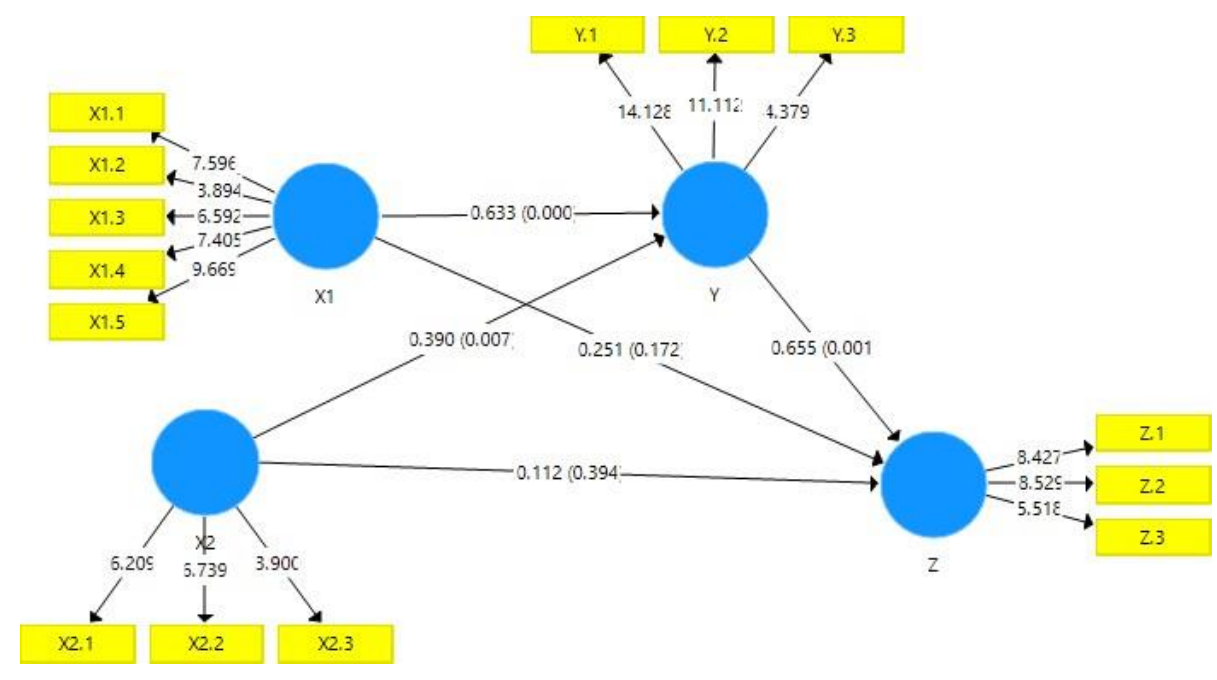

\section{Gambar 1 \\ hasil uji hipotesis \\ Sumber: data primer diolah, 2021}

Berdasarkan hasil di atas maka dapat diperoleh uraian bahasan sebagai berikut ini:

1. Pengaruh variabel X1 terhadap $\mathrm{Y}$ memiliki nilai P-Values sebesar $0.000<0,05$, sehingga dapat dinyatakan bahwa pengaruh antara X1 terhadap $\mathrm{Y}$ adalah signifikan.

2. Pengaruh variabel $X 1$ terhadap $Z$ memiliki nilai $P-V a l u e s$ sebesar $0.172>0,05$, sehingga dapat dinyatakan bahwa pengaruh antara $\mathrm{X} 1$ terhadap $\mathrm{Z}$ adalah tidak signifikan.

3. Pengaruh variabel X2 terhadap $\mathrm{Y}$ memiliki nilai P-Values sebesar $0.007<0,05$, sehingga dapat dinyatakan bahwa pengaruh antara X2 terhadap Y adalah signifikan.

4. Pengaruh variabel X2 terhadap Z memiliki nilai P-Values sebesar $0.394>0,05$, sehingga dapat dinyatakan bahwa pengaruh antara $\mathrm{X} 2$ terhadap $\mathrm{Z}$ adalah tidak signifikan.

5. Pengaruh variabel $\mathrm{Y}$ terhadap $\mathrm{Z}$ memiliki nilai $\mathrm{P}$-Values sebesar $0.001<0,05$, sehingga dapat dinyatakan bahwa pengaruh antara $\mathrm{Y}$ terhadap $\mathrm{Z}$ adalah signifikan.

Tabel 2

Hasil Pengaruh Tidak Langsung

$\begin{array}{lllll}\text { Original } & \text { Sample Mean } & \begin{array}{l}\text { Standard } \\ \text { Deviation } \\ \text { Sample (O) }\end{array} & \begin{array}{l}\text { T Statistics } \\ (\text { STDEV) }\end{array} & \text { P Values } \\ & & & \end{array}$

\begin{tabular}{llllcc}
\hline $\mathbf{X 1}$-> $\mathbf{Y}$ & & & & & \\
\hline $\mathbf{X 1}$-> $\mathbf{Z}$ & 0.414 & 0.374 & 0.139 & 2.977 & $\mathbf{0 . 0 0 3}$ \\
\hline $\mathbf{X} 2$-> Y & & & & & \\
\hline $\mathbf{X} 2$-> $\mathbf{Z}$ & 0.255 & 0.239 & 0.122 & 2.095 & $\mathbf{0 . 0 3 7}$ \\
\hline
\end{tabular}




\begin{tabular}{llllll}
\hline & $\begin{array}{l}\text { Original } \\
\text { Sample (O) }\end{array}$ & $\begin{array}{l}\text { Sample Mean } \\
(\mathrm{M})\end{array}$ & $\begin{array}{l}\text { Standard } \\
\text { Deviation } \\
(\text { STDEV })\end{array}$ & $\begin{array}{l}\text { T Statistics } \\
(|\mathrm{O} / \mathrm{STDEV}|)\end{array}$ & P Values \\
\hline $\mathrm{Y}>\mathrm{Z}$ & & & & & \\
\hline
\end{tabular}

\section{Sumber: Data primer diolah, 2021}

Berdasarkan tabel di atas diperoleh nilai koefisien pengaruh tidak langsung variabel X1 terhadap Z sebesar $0.003<0.05$, dengan demikian dapat dinyatakan bahwa $\mathrm{Y}$ memediasi pengaruh antara X1 terhadap Z.

Selanjutnya, nilai koefisien pengaruh tidak langsung variabel $\mathrm{X} 2$ terhadap $\mathrm{Z}$ sebesar $0.037<0.05$, dengan demikian dapat dinyatakan bahwa $\mathrm{Y}$ memediasi pengaruh antara X2 terhadap Z.

Pada penelitian terdahulu yang berjudul pengaruh minat belajar terhadap prestasi belajar matematika di SMP N 160 Jakarta dimana minat belajar termasuk dalam kategori kuat, karena berdasarkan perhitungan dan pengolahan data diperoleh dengan nilai rata-rata sebesar 72,7; nilai modus sebesar 71,002; median sebesar 72,448 dan simpangan baku sebesar 8,499. Sehingga dapatdisimpulkan bahwa minat belajar siswa di SMP N 160 Jakarta tergolong tinggi. Prestasi belajar matematika siswa termasuk dalam kategori kuat, karena berdasarkan perhitungan dan pengolahan data diperoleh nilai rata-rata sebesar 79,438; nilai modus sebesar 79,642; median sebesar 79,558 dan simpangan baku sebesar 9,611.

Sehingga disimpulkan bahwa prestasi belajar matematika di SMP N 160 Jakarta tergolong sedang. Koefisien korelasi antara minat belajar dengan prestasi belajar matematika sebesar 0,706. Angka ini termasuk dalam kategori korelasi yang kuat, sehingga dapat diartikan bahwa terdapat hubungan positif yang lemah antara minat belajar dengan prestasi belajar matematika siswa, dimana nilai koefisien determinasi sebesar 0,498; yang artinya variabel minat belajar memberikan kontribusi sebesar 49,8\% terhadap penambahan prestasi belajar matematika siswa.

Penelitian terdahulu tentang Pengaruh motivasi berprestasi, minat belajar matematika, dan sikap belajar matematika terhadap hasil belajar matematika pada siswa sman 2 watampone. Berdasarkan hasil penelitian dan pembahasan, dapat disimpulkan bahwa hasil belajar matematika, motivasi belajar matematika, minat belajar matematika, dan sikap belajar matematika siswa kelas X SMAN 2 Watampone termasuk dalam kategori tinggi. Kemudian dilihat dari pengaruhnya bahwa motivasi belajar matematika, minat belajar matematika dan sikap belajar matematika secara bersama-sama mempunyai pengaruh positif terhadap hasil belajar matematika siswa kelas X SMAN 2 Watampone. Sedangkan motivasi belajar matematika, minat belajar matematika, dan sikap belajar matematikamempunyai pengaruh positif terhadap hasil belajar matematika siswa kelas X SMAN 2 Watampone. 


\section{Kesimpulan}

Minat belajar mendeterminasi secara langsung terhadap kreativitas mahasiswa Institut Agama Islam Abdullah Said Batam. Sikap mendeterminasi secara langsung terhadap kreativitas mahasiswa Institut Agama Islam Abdullah Said Batam. Kreativitas mendeterminasi secara langsung terhadap prestasi belajar mahasiswa Institut Agama Islam Abdullah Said Batam. Minat belajar tidak mendeterminasi secara langsung terhadap prestasi belajar mahasiswa Institut Agama Islam Abdullah Said Batam. Sikap tidak mendeterminasi secara langsung terhadap prestasi belajar mahasiswa Institut Agama Islam Abdullah Said Batam.

Berdasarkan simpulan, maka dapat rekomendasi yang dapat di berikan ialah Institut Agama Islam Abdullah Said Batam perlu mengevaluasi secara terstruktur dalam meningkatkan minat belajar dan kreatifitas sehingga prestasi belajar mahasiswa dapat meningkat dan menghasilkan lulusan yang berkompeten serta siap berkompetisi dalam dunia kerja. 


\section{BIBLIOGRAFI}

Arifin, Sadriwanti. (2018). Pengaruh Minat dan Kreativitas Belajar Matematika terhadap Hasil Belajar Matematika Siswa Kelas X SMA. Histogram, 2(1), 5970.Google Scholar

Imam, Hanafi. (2021). Kepemimpinan Visioner Kepala Sekolah Di Smp Istiqomah Sambas Purbalingga. Iain Purwokerto. Coresspondesse. Google Scholar

Indrayani, Henni. (2012). Penerapan Teknologi Informasi dalam Peningkatan Efektivitas, Efisiensi dan Produktivitas Perusahaan. Jurnal El-Riyasah, 3(1), 4856. Google Scholar

Maesaroh, Siti. (2013). Peranan metode pembelajaran terhadap minat dan prestasi belajar pendidikan agama Islam. Jurnal Kependidikan, 1(1), 150-168. Google Scholar

Muhibbin, Syah. (2010). Psikologi pendidikan dengan pendekatan baru. Bandung: PT Remaja Rosdakarya. Google Scholar

Nurhasanah, Siti, \& Sobandi, Ahmad. (2016). Minat belajar sebagai determinan hasil belajar siswa. Jurnal Pendidikan Manajemen Perkantoran (JPManper), 1(1), 128135. Google Scholar

Pulungan, Muhammad Syukri. (2015). Self-regulated learning: upaya peningkatan prestasi akademik. HIKMAH: Jurnal Ilmu Dakwah Dan Komunikasi Islam, 2(2), 133-148. Google Scholar

Qomariah, Siti Saptari, \& Sudiarditha, I. Ketut R. (2016). Kualitas media pembelajaran, minat belajar, dan hasil belajar siswa: studi pada mata pelajaran ekonomi di kelas X IIS SMA Negeri 12 Jakarta. Jurnal Pendidikan Ekonomi Dan Bisnis (JPEB), 4(1), 33-47. Google Scholar

Rivaldo, Yandra. (2021). Leadership and Motivation to Performance through Job Satisfaction of Hotel Employees at D'Merlion Batam. The Winners, 22(1). Google Scholar

Saifuddin Azwar. (2010). Metode Penelitian. Yogyakarta: Pustaka Pelajar.

Sanusi, Anwar. (2011). Metodologi penelitian bisnis. Jakarta: Salemba Empat. Google Scholar

Slameto. (2010). Belajar yang Mempengaruhinya, Faktor-Faktor. In Rineka Cipta. Jakarta. Google Scholar

Sugiyono. (2017). Metode Penelitian Kuantitatif, Kualitatif, dan R\&D. Bandung: Alfabeta Surya. Google Scholar 
Nurhayati, Lias Hasibuan, Kemas Imron Rosyadi

Sukmadinata, Nana Syaodih. (2019). Landasan psikologi proses pendidikan. Google Scholar

Suryosubroto. (2008). Proses Belajar Mengajar Di Sekolah. Jakarta: PT Rineka Cipta Susanto. Google Scholar

Susilowati. (2015). Hubungan Antara Kreativitas Dan Sikap Belajardengan Prestasi Belajar Mahasiswa Dijurusan Ortotik Prostetik Politeknik Kesehatan Surakarta. Jurnal Kesehatan, VI(1). Google Scholar

Syarif, Izuddin. (2012). Pengaruh model blended learning terhadap motivasi dan prestasi belajar siswa SMK. Jurnal Pendidikan Vokasi, 2(2). Google Scholar

Syarifuddin, Chaeruni Rezki. (2016). Pengaruh Pemberian Penguatan Positif Terhadap Sikap Belajar Peserta Didik Pada Mata Pelajaran Bahasa Indonesia Di Mi Darul Istiqamah Kecamatan Pattalassang Kabupaten Gowa. Auladuna: Jurnal Pendidikan Dasar Islam, 3(2), 60-70. Google Scholar

Tadjab. (1994). Ilmu Jiwa Pendidikan. Surabaya: Karya Abditama.

Walgito, Bimo. (2004). Pengantar psikologi umum. Yogyakarta: Andi Offset. Google Scholar

\section{Copyright holder:}

Nurhayati, Lias Hasibuan, Kemas Imron Rosyadi (2021)

First publication right:

Syntax Idea

This article is licensed under:

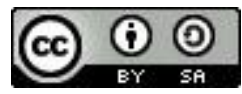

